\title{
Asymmetric tonsil hypertrophy may be a sign of Burkitt's lymphoma
}

\section{Asimetrik tonsil hipertrofisi Burkitt lenfomanın bir bulgusu olabilir}

\author{
Sedat Aydın' ${ }^{1}$ Eren Boldaz ${ }^{1}$ \\ ${ }^{1}$ T.C. Sağlık Bilimleri Üniversiesi Kartal Dr. Lütfi Kırdar Kartal Eğitim Ve Araştırma Hastanesi, Kbb Kliniği, İstanbul
}

Dergiye Ulaşma Tarihi: 30.06.2018 Dergiye Kabul Tarihi:04.02.2019 Doi: 10.5505/aot.2019.47550

A 4-year-old boy has had cryptic membranous tonsillitis episode 5-6 times since last year and applied to our Ear Nose and Throat (ENT) clinic for the last 3 months of onset of odynophagia. Patient showed asymmetric hypertrophy of the left tonsil (grade 4) and the appearance of ulcerated surface was observed (Figure 1). In computerized tomography; (sections crossing oropharynx levels) it was interpreted as a mass that could be malignant in the soft tissue density of the contour of the left parapharyngeal lesion of approximately $41 \times 31 \mathrm{~mm}$. Tonsillectomy was performed with general anesthesia. Histopathologic and immunohistochemical findings were compatible with Burkitt's lymphoma (BL), CD20 (+) and Ki67 proliferation index were $90 \%$ positive (Figure 2 ). The patient was referred to the oncology clinic for chemotherapy.

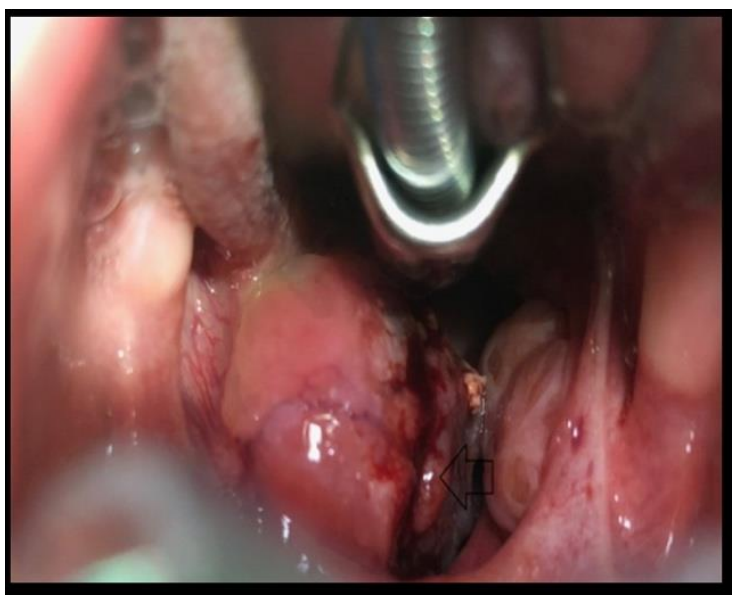

Figure 1. Left palatine tonsil with asymmetric hypertrophy and appearance of ulcer surface.

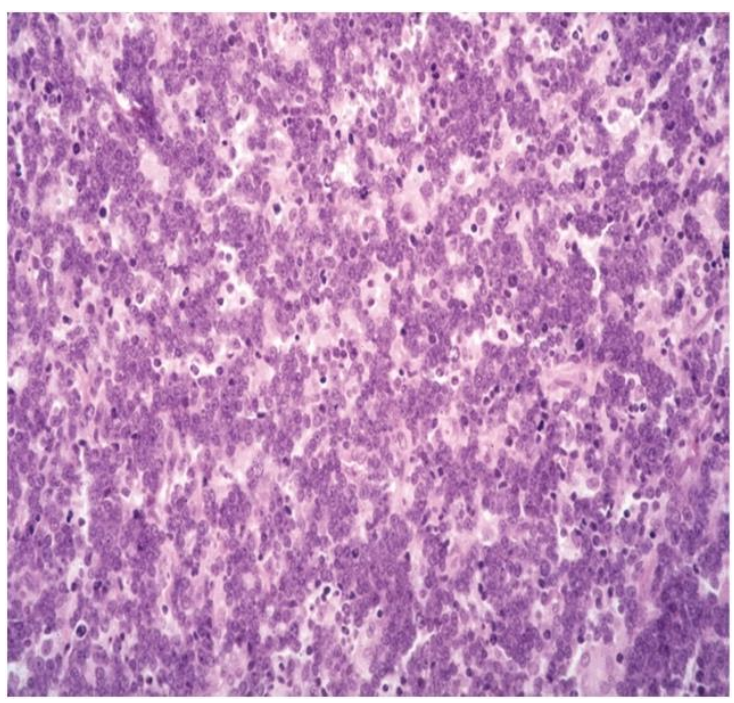

Figure 2: Lymphoid infiltration under the squamous epithelium and a characteristic starshaped sky pattern of Burkitt's lymphoma.

Hodgkin's and non-Hodgkin's lymphomas (NHL) are the second most common after squamous cell carcinoma in head and neck cancer. Three different forms of BL, which are associated with endemic (africa), sporadic (nonafrica) and immunodeficiency, have been described as one of the most aggressive and rare species of the NHL group. BL localized in the head and neck region, appears to be only 2-3 cases per million per year in the US and Europe and has more than $50 \%$ incidence of abdominal involvement (1). Our case, sporadic BL, showed palatine tonsil involvement as a very rare localization, unlike abdominal involvement.

In a study of 2504 patients with oropharyngeal lymphoma; the mean age was 
60.5 years, the most common localization was palatine tonsil, and the most frequent type was diffuse large cell lymphoma with $56.9 \%$ (3). Extranodal NHLs have a variable clinical course and prognosis due to the primary involvement region. Early stage palatine tonsil localization has a better prognostic value than other extranodal involvements and is associated with the success of the treatment. Early detection of such tumors with rapid growth and aggressive chemotherapy results in survival rates of up to $90 \%$ (1-3).

BL is considered to be one of the aggressive lymphoma types because it has the shortest duplication time of about 24 hours and early diagnosis and effective treatment are very important in terms of prognosis. The BL form involving the palatine tonsils usually manifests with unilateral painless tonsil growth, a feeling of discomfort in the throat, and sometimes with symptoms such as odynophagia. Cervical lymphadenopathy can be found in $60 \%$ of patients. Because these symptoms can also be observed in clinical situations such as acute URIs and peritonsillar abscess in the childhood age group, the diagnosis may be delayed $(4,5)$. The approach of ENT physicians is mostly tonsillectomy in patients with unilateral asymmetric palatine tonsils hypertrophy because of the malignancy doubt. Lymphoma involving the palatine tonsils leads to asymmetric hypertrophy despite clinically more submucosal mass formation $(2,4)$. Bizzell et al. reported that the histopathological examination of the tonsillectomy specimens of 8087 patients revealed a $0.05 \%$ incidence of lymphoma and the meta-analysis performed by Randall et al. showed that the histopathologic examination of 54901 patients had $0.087 \%$ of the malignancy incidence. 48 of these 54 patients $(88 \%)$ were asymmetric unilateral tonsil hypertrophy, cervical lymphadenopathy and abnormal appearence of palatine tonsils $(5,6)$.

Therefore, we can say that routine histopathologic examination of tonsillectomy specimens is not necessary but histopathologic examination is necessary in case of clinical suspicion of malignancy.

As a result, family physicians, pediatricians and otolaryngologists need to consider a rare and aggressive malignancy, such as a $\mathrm{BL}$, in the face of rapidly developing sore throat, fever, swallowing difficulty, asymmetric tonsil hypertrophy, cervical lymphadenopathy and abnormal tonsil' appearance, thus leading to early detection of BL by tonsillectomy and subsequent histopathological examination.

\section{REFERENCES}

1. Epstein JB, Epstein JD, Le ND, Gorsky M. Characteristics of oral and paraoral malignant lymphoma: A population-based review of 361 cases. Oral Surg Oral Med Oral Pathol Oral Radiol Endod 2001; 92: 519-25.

2. Banthia V, Jen A, Kacker A. Sporadic Burkitt's lymphoma of the head and neck in the pediatric population. Int J Pediatr Otorhinolaryngol 2003; 67: 59-65.

3. Rayess HM, Nissan M, Gupta A, Carron MA, Raza SN, Fribley AM. Oropharyngeal lymphoma: A US population based analysis. Oral Oncol. 2017;73:147151. doi: 10.1016/j.oraloncology.2017.08.018.

4. Wang TF, Bartlett NL. Lymphomas of the Head and Neck. In: Haughey BJ, Robbins KT, editors. Cummings Otolaryngology Head and Neck Surgery, Philadelphia : Saunders; 2015, p 1805-15.

5. Bizzell JG, Richter GT, Bower CM, Woods GL, Nolder AR. Routine pathologic examination of tonsillectomy specimens: A 10-year experience at a tertiary care children's hospital. Int J Pediatr Otorhinolaryngol 2017; 102: 86-89. doi: 10.1016/j.ijporl.2017.09.012.

6. Randall DA, Martin PJ, Thompson LDR. Routine histologic examination is unnecessary for tonsillectomy or adenoidectomy. Laryngoscope. 2007;117:1600-4. 